\title{
Os impactos das identidades transgênero na sociabilidade de travestis e mulheres transexuais
}

\section{The impacts of transgender identities in sociability of travestis and transsexual women}

\author{
Rodrigo Gonçalves Lima Borges da Silva1, Waldez Cavalcante Bezerra ${ }^{2}$, \\ Sandra Bomfim de Queiroz ${ }^{3}$
}

http://dx.doi.org/10.11606/issn.2238-6149.v26i3p364-372

\begin{abstract}
Silva RGLB, Bezerra WC, Queiroz SB. Os impactos das identidades transgênero na sociabilidade de travestis e mulheres transexuais. Rev Ter Ocup Univ São Paulo. 2015 set.-dez.;26(3):364-72.
\end{abstract}

RESUMO: Este artigo é resultado de uma pesquisa realizada no município de Maceió-AL, entre março de 2013 a setembro de 2014, e teve como objetivo geral compreender os impactos das identidades transgênero na sociabilidade de travestis e mulheres transexuais. Trata-se de um estudo qualitativo, que utilizou três fontes para registros e produção dos dados: diário de campo, observação participante e grupo focal. Os dados foram analisados por meio da análise de conteúdo. A apresentação e discussão dos resultados se deram a partir de três categorias temáticas: $A$ família como primeiro grupo que exclui; A escola como lócus de reprodução do preconceito e discriminação; A rua que acolhe e vulnerabiliza. Os resultados evidenciaram que a expressão das identidades transgênero repercute negativamente na sociabilidade das travestis e transexuais, empurrando-as para uma situação de vulnerabilidade social e gerando sofrimentos diversos.

DESCRITORES: Pessoas transgênero; Identidade de gênero; Participação social; Travestismo; Transexualismo; Vulnerabilidade social; Mulheres.
Silva RGLB, Bezerra WC, Queiroz SB. The impacts of transgender identities in sociability of travestis and transsexual women. Rev Ter Ocup Univ São Paulo. 2015 Sept.Dec.;26(3):364-72.

\begin{abstract}
This paper is the result of research conducted in the city of Maceió-AL, Brazil, between March 2013 and September 2014, which aimed to understand the impacts of transgender identities on the sociability of travesties and transsexual women. In this qualitative field study, we used three sources to produce and register data: field diary, participant observation and focus group. Data were analyzed using content analysis. The presentation and discussion of results used three thematic categories: the family as the first group that excludes; the school as a reproductive locus of prejudice and discrimination; the street that welcomes and increases vulnerability. The results showed that the expression of transgender identities produces negative repercussions on the sociability of travesties and transsexuals, exposing them to social vulnerability and various types of suffering.
\end{abstract}

KEYWORDS: Transgendered persons; Gender identity; Social participation; Transvestism; Social vulnerability; Transsexualism; Women.

\footnotetext{
Este artigo apresenta parte das reflexões contidas no trabalho de conclusão do Curso de Terapia Ocupacional da UNCISAL “Os processos de feminilidade nas travestis e mulheres transexuais e a repercussão nos espaços de sociabilidade".

1. Universidade Estadual de Ciências da Saúde de Alagoas (UNCISAL), Acadêmico do Curso de Terapia Ocupacional.

2. Universidade Estadual de Ciências da Saúde de Alagoas (UNCISAL), Curso de Terapia Ocupacional, Maceió, AL, Brasil.

3. Universidade Estadual de Ciências da Saúde de Alagoas (UNCISAL), Maceió, AL, Brasil.

Endereço para correspondência: Waldez Cavalcante Bezerra. Rua Magda Daniele, 160, Santa Lúcia. Maceió, Al. CEP: 57082-116. E-mail: waldezto@yahoo.com.br.
} 


\section{INTRODUÇÃO}

$\mathbf{O}$ $s$ estudos de gênero podem ser considerados como resultados das lutas libertárias iniciadas nos anos 1960, mais particularmente dos movimentos sociais de 1968. As mulheres, participantes destes movimentos, perceberam que, apesar de militarem em pé de igualdade com os homens, tinham papel secundário neles. No Brasil o campo de estudos de gênero ou relações de gênero emergiu nos anos 1970/1980 em torno da problemática da condição feminina ${ }^{1}$.

Pesquisadores da antropologia discutiram a distinção entre diferença sexual e a sexualidade, enquanto construções sociais que diferem culturalmente. Em algumas culturas é possível relacionar o gênero, em conjunto ou separadamente com a identidade sexual ${ }^{(1)}$, de modo que a construção dos símbolos e conceitos do que é definido como gêneros feminino e masculino são produtos histórico-sociais ${ }^{2,3,4}$.

Bruns e Pinto ${ }^{5}$ defendem que o gênero é uma construção social e, portanto, histórica de modo que poderse-ia supor que esse conceito é plural e que haveriam conceitos de feminino e masculino diversos. Para Peres ${ }^{6}$ as relações de gênero participam dos modos de subjetivação, considerando as imagens, discursos e sentidos que são construídos nos cotidianos das pessoas, determinando diversas concepções de mundo e de relações.

Contudo, a noção de gênero como uma construção social não é a única encontrada nas sociedades. Existem perspectivas, ainda dominantes em algumas sociedades, que estabelecem uma relação binária e compreendida como supostamente natural acerca da construção do gênero, que define o binômio homem/mulher, masculino/feminino.

Segundo Jesus ${ }^{8}$ o binarismo é a crença construída em uma dualidade simples e fixa entre indivíduos dos sexos feminino e masculino. Essa ideia está associada à de que existiria uma relação direta entre as categorias sexo (biológica) e gênero (psicossocial). O cissexismo é a ideologia resultante desse binarismo, que se fundamenta na crença de que características biológicas relacionadas ao sexo são correspondentes a características psicossociais relacionadas ao gênero ${ }^{8}$.

Neste artigo serão utilizados os conceitos propostos por Jesus: expressão de gênero, identidade de gênero, papel de gênero e orientação sexual. Expressão de gênero é a forma como a pessoa apresenta a sua aparência e seu comportamento, de acordo com as expectativas sociais de um determinado gênero, depende da cultura em que a pessoa vive. Identidade de gênero é o gênero com o qual uma pessoa se identifica, que pode ou não concordar com o gênero que lhe foi atribuído quando de seu nascimento, ou seja, uma pessoa pode nascer com um sexo biológico (homem ou mulher) e se identificar com o gênero oposto (masculino ou feminino). Orientação sexual é atração afetivo-sexual por alguém, vivência interna relativa à sexualidade (heterossexual, homossexual ou bissexual). Identidade de gênero e orientação sexual são dimensões diferentes, que não devem ser confundidas. O papel de gênero é o modo de agir em determinadas situações conforme o gênero atribuído, ensinado às pessoas desde $o$ nascimento; é de cunho social e não biológico ${ }^{8}$.

Dentre as pessoas transgênero encontram-se as travestis e mulheres transexuais. Em sua maioria, as travestis são pessoas que nascem com o sexo biológico masculino, com aparência física masculina, mas que não se identificam como homem. Tendem a construir uma identidade de gênero feminina. Já as mulheres transexuais são pessoas que reivindicam o reconhecimento social e legal como mulher. É um individuo que tem a convicção de pertencer ao sexo oposto, ou seja, seu sexo psíquico se encontra em discordância com o biológico ${ }^{5,8,9}$.

Durante o processo de construção de suas identidades, as travestis e transexuais se diferenciam em alguns pontos, contudo ambas carregam em si símbolos e elementos femininos. A construção do corpo feminino começa muito cedo, na infância ou adolescência, quando percebem e se identificam com símbolos da figura feminina. São várias as mudanças corporais, desde as primeiras intervenções, como as unhas pintadas, maquiagem, o uso de perucas, sapatos e roupas, até os processos mais profundos e significantes de mudança, como os pelos e cabelos, a voz, a arte de esconder o pênis sob a roupa, as cirurgias plásticas, a aplicação de hormônios e, no caso das transexuais, a cirurgia de trangenitalização ou redesignação sexual ${ }^{(2)}$, uma vez que elas buscam esta cirurgia para adequar a aparência física ao seu sexo psicológico. Ambas buscam, em todo seu processo de transformação, aquilo que chamam de feminino ${ }^{2,9}$.

No meio social, todas as pessoas são diferentes no entanto, na vivência social nem sempre isso é considerado.

(1) Identidade sexual é o senso de si mesmo como homem ou mulher?.

(2) A transexualidade é considerada pela Organização Mundial de Saúde (OMS) como um transtorno de identidade de gênero, estando catalogada no Código Internacional de Doenças com o CID de n 10-F64.0. 
As pessoas que não se enquadram dentro das perspectivas que o imaginário social dita em relação às normas de gênero e ao que vem a ser a representação social da figura do masculino e do feminino são discriminadas.

A Teoria Queer foi elaborada como forma de (re) pensar novas e antigas perspectivas da construção social dos mecanismos que levam a discriminação e o preconceito com as identidades transgênero, e na tentativa de problematizar a desnaturalização das questões que envolvem os sexos biológicos. Essa teoria emergiu nos Estados Unidos, durante os anos 1980 a partir do encontro entre uma vertente dos estudos culturais, o pós-estruturalismo francês, e o feminismo de "terceira onda". Em 1990 a denominação Teoria Queer foi usada pela primeira vez por Teresa de Lauretis para contrastar o empreendimento analítico que um conjunto de pesquisadores desenvolvia em oposição crítica aos estudos sociológicos sobre minorias sexuais e de gênero ${ }^{10,11}$.

Queer é uma palavra da língua inglesa, cujo sentido original é 'estanho', 'esquisito'. O termo foi usado como forma de ofensa e discriminação com as pessoas consideradas diferentes dos padrões normativos relacionados ao binarismo sexual, atualmente a palavra ganhou sentidos positivos junto com o debate da desnaturalização das identidades sexuais e de gênero e contribui para entender as formas de organização das identidades e, também, a noção de diferença ${ }^{10}$.

A Teoria Queer se opõe as perspectivas excludentes e lida com o gênero como algo cultural. Considera que o masculino e o feminino presente em homens e mulheres, de forma que cada pessoa tem características que podem se qualificar como masculinas ou femininas, independente do sexo biológico ${ }^{10}$.

No Brasil, a incorporação da Teoria Queer se iniciou no final da década de 1990 na área dos estudos de gênero e sexualidade. $\mathrm{O}$ marco de sua recepção pode ser estabelecido em 2001, quando Guacira Lopes Louro publicou, na Revista Estudos Feministas, o artigo "Teoria Queer: uma política pós-identitária para a educação". Desde então alguns teóricos queer encontraram nas obras de Michel Foucault e Jacques Derrida conceitos e método ${ }^{11}$.

Segundo Miskolci ${ }^{11}$ o objetivo era explicitar os processos que criam sujeitos considerados normais e adaptados, bem como os considerados ilegítimos, rotulados como anormais e alocados na margem do social. Foi essencial para o desenvolvimento da Teoria Queer, o conceito de suplementaridade criado por Derrida. Segundo ele, nossa linguagem opera em binarismos, de forma que o hegemônico só se constrói como oposição a algo inferiorizado e subordinado. Assim, a heterossexualidade só existe em oposição à homossexualidade, compreendida como seu negativo. A homossexualidade é o outro sem o qual o hegemônico não se constitui, nem tem como descrever a si próprio.

A partir da ótica da Teoria Queer, de contestação a qualquer padrão normatizador, as pessoas que fogem ao padrão heteronormativo não são inteligíveis para os padrões hegemônicos de gênero fundamentados no binarismo e se tornam alvo de preconceito e/ou discriminação em função da sua identidade de gênero, prática esta denominada de transfobia e que não deve ser confundida com a homofobia ${ }^{12}$. Pessoas transgênero são alvo de preconceito, não atendimento de direitos fundamentais e de exclusão estrutural, que se manifesta na dificuldade de acesso à educação, mercado de trabalho qualificado e até uso de banheiros, além de sofrerem violências variadas, ameaças, agressões e homicídios ${ }^{13}$.

Levando em consideração a crença de que o corpo é um atributo natural e que define a identidade de homens e mulheres enquanto pessoas de um sexo ou de outro, as mudanças corporais realizadas pelas travestis e transexuais implicam em dificuldade de convivência nos espaços sociais normatizados. A não aceitação familiar as leva a morar em outros ambientes. $\mathrm{O}$ acesso aos serviços de saúde, às políticas públicas e à circulação, em diferentes territórios e instituições, também é dificultado. Sem muita opção de moradia e meios de se sustentar, podem ir viver no contexto da rua e da noite e encontrar na prostituição um meio de sobrevivência, o que as coloca em situação de risco ${ }^{14}$.

A partir do reconhecimento desse conjunto de aspectos, foi desenvolvido o estudo que teve como objetivo geral compreender os impactos das identidades transgênero na sociabilidade de travestis e transexuais. A palavra sociabilidade está sendo usada como sinônimo de qualquer espécie de interação social; ela é fluida e as práticas e os espaços de sociabilidade sofrem mutações quando o contexto ao seu redor se altera ${ }^{15}$.

Os objetivos específicos foram: identificar os principais contextos de vida afetados pelas identidades transgênero; e identificar as rupturas/conflitos gerados por estas identidades em tais contextos. O estudo foi realizado para elaboração de trabalho de conclusão de curso de graduação em Terapia Ocupacional, na Universidade Estadual de Ciências da Saúde de Alagoas (UNCISAL).

A pesquisa de campo foi realizada no município de Maceió-AL, no período de março de 2013 a setembro de 2014. A aproximação com o campo se deu a partir do $1^{\circ}$ Seminário de Travestis e Transexuais Negras da Região Nordeste, realizado em 2013. Posteriormente, o projeto de pesquisa foi apresentado para a Associação das Travestis e 
Transexuais de Alagoas (ASTTAL) que aprovou a realização da pesquisa. O estudo foi aprovado pelo Comitê de Ética em Pesquisa com Seres Humanos da UNCISAL, com protocolo de número 23519713.8.0000.5011.

\section{PERCURSO METODOLÓGICO}

Trata-se de uma pesquisa com abordagem qualitativa, descritiva e aplicada. Quanto aos procedimentos, é uma pesquisa de campo, em composição metodológica com elementos das pesquisas participante e etnometodológica, que buscou dialogar com os referenciais teóricometodológicos da Complexidade e Multirreferencialidade e os Estudos Culturais, além de autores com aporte teórico específicos relacionados com a temática problematizada.

Participaram do estudo cinco integrantes da ASTTAL, definidas por conveniência, que se denominaram travestis ou transexuais, dentre as que se disponibilizaram em participar do estudo.

O trabalho de campo consistiu no acompanhamento do cotidiano das travestis e transexuais de maio a julho de 2014. Neste período foram realizadas visitas domiciliares, participação nas reuniões da ASTTAL, acompanhamento dos processos de montagem, das atividades de lazer e trabalho das mesmas. Os instrumentos de coleta e de registro de dados foram a observação participante, o diário de campo, e o grupo focal.

A observação participante se deu por meio da inserção no grupo pesquisado e na participação, em várias situações, nas vivências peculiares ao universo do grupo, tais como reuniões da associação, ensaios e preparação das apresentações culturais ${ }^{(3)}$ que elas realizam, além de atividades de lazer. $\mathrm{O}$ diário de campo permitiu registrar desde o processo de aproximação com o campo de pesquisa e com o grupo estudado, até os processos mais íntimos vivenciados com o mesmo.

Além disso, foi desenvolvido grupo focal, formado por três travestis e dois transexuais. As participantes do grupo focal foram as mesmas que tiveram alguns das suas vivências cotidianas compartilhadas com os pesquisadores, o que permitiu a construção de um vínculo favorável à coleta de informações.

O grupo focal foi realizado na casa de uma das participantes. Para provocar a discussão, foram utilizadas duas perguntas disparadoras (Quais as primeiras lembranças que vocês têm envolvendo a sua sexualidade? Vocês poderiam falar sobre as intervenções realizadas para transformar o seu corpo?). Para aprofundamento as questões foram complementadas e foi estimulada a participação de todas.

Para a análise e interpretação dos dados, foi utilizada a técnica de análise de conteúdo, na modalidade temática, que consistiu em: leitura exaustiva do material para identificação das ideias centrais, interpretação dos sentidos de tais ideias, agrupamento das mesmas em categorias, comparação entre os diferentes núcleos de sentido encontrados, classificação dos núcleos de sentido em eixos mais abrangentes em torno dos quais giram as discussões e redação das sínteses interpretativas de cada tema.

\section{RESULTADOS}

As travestis e transexuais participantes, ao total de cinco, tinham idades que variavam de 21 a 48 anos de idade. Todas residem em bairros populares da cidade de Maceió e vivem da renda gerada pela prostituição noturna e pelas atividades do grupo Trans Show. São integrantes da ASTTAL e participam ativamente das atividades desta, sendo uma delas a presidente da associação.

O trabalho de campo revelou que as participantes compartilham um contexto de vida marcado pela vulnerabilidade, seja pela situação de trabalho informal, que gera inúmeras carências materiais, ou pela história de vida repleta de rupturas relacionais, principalmente com os familiares. Nesse contexto, a ASTTAL se constitui um ponto fundamental da rede de apoio social delas, fornecendo suporte material (doação de cestas básicas, passagens de ônibus, etc.), afetivo e social, evitando que muitas caiam para a desfiliação social.

A partir da análise de conteúdo emergiram três categorias temáticas: A família como primeiro grupo que exclui; A escola como lócus de reprodução do preconceito e discriminação; A rua que acolhe e vulnerabiliza. Estas categorias giram em torno dos principais contextos de vida (família, escola, rua) afetados pela condição transgênero e que marcam as trajetórias de vida das participantes, segundo os relatos das mesmas.

(3) O TRANS SHOW é um grupo sem fins lucrativos do estado de Alagoas, organizado por membros da ASTTAL, e tem por finalidade desenvolver shows artísticos e arrecadar recursos financeiros, como alternativa a prostituição. 


\section{DISCUSSÃO}

\section{A família como primeiro grupo que exclui}

As participantes relataram que as primeiras experiências de exclusão ocorreram na família, a partir do momento em que começaram a manifestar a diferença, incrementada pelo desejo de se transformar em travesti ou mudar de sexo. Neste momento, nenhuma das famílias do grupo estudado conseguiu expressar aceitação, acolhimento e estabelecer uma relação de convívio harmoniosa.

A minha familia foi aquela coisa, eu larguei logo cedo, minha mãe faleceu eu tinha 13 para 14 anos, então pronto, eu tive uma vida só mesmo (Participante 1).

Quando a gente é menor, mesmo sem ter tomando alguma decisão na vida, mesmo sem querer a homossexualidade, a gente não sabe o preconceito; isso começa na família, os primos são os primeiros a dizerem: Tome jeito de homem! Fale que nem homem! Fale grosso! É coisa que já trazem da infância (Participante 2).

Procurei minha familia, fui rejeitada pelos meus irmãos lá do Maranhão, em 2008. O preconceito começa pela própria família. Colocaram-me para fora de casa! Ninguém quer aceitar a condição de eu ser trans. Na cabeça da família da gente, você é homem e não deixa de ser homem, não tem essa mentalidade de aceitar a sua orientação sexual, fui humilhada! (Participante 3).

Para elas, a família, ao invés de acolher, tornou-se o primeiro grupo de sociabilidade produtor de exclusão, onde teve início o rompimento de vínculos e o processo de estigmatização, deixando as travestis e transexuais vulneráveis, marcadas negativamente e depreciadas ao ponto de serem desprovidas do direito a ter direitos. Os processos depreciativos vividos por elas influem em toda a organização de suas subjetividades, construídas ao longo das relações que estabelecem com os outros, com o mundo e consigo mesmas.

Dentre as participantes apenas uma travesti voltou a viver com sua família; as demais relatam que saíram de casa na adolescência, após começarem os primeiros investimentos para obter uma aparência feminina.

Quando eu tomei a iniciativa de tomar hormônio, comecei a me descobrir... A me assumir, eu fugi de casa! (Participante 2).

Ai eu comecei a tomar hormônio, comecei a mudar meu corpo, foi quando eu me lancei [saiu de casa] (Participante 3).
A percepção de que tem algo acontecendo de forma diferente do que ocorre com as outras pessoas marca algumas travestis e transexuais. A descoberta do corpo sexuado é um momento de atribuição de sentido para as várias surras, insultos e rejeições familiares. Esse momento gera um espanto, de modo que a mente e o corpo não podem ir contra o que elas desejam, que é ser o que elas realmente são. E, nesse momento, ser requer muita energia e coragem para enfrentar o contexto ao seu redor.

As memórias da infância como crianças trans apontam para experiências comuns da vivência da transgeneridade entre os diferentes sujeitos, com aspectos negativos, como o sentimento do "estranho", remetendo a uma internalização, pelas crianças, do discurso binarista de gênero que busca controlar e evitar que os limites atribuídos aos sexos biológicos sejam rompidos, e que sua falibilidade seja evidenciada ${ }^{16}$.

A descoberta de que ter um pênis e não conseguir agir de acordo com as expectativas sociais, ou seja, não conseguir desenvolver o gênero "apropriado" para seu sexo, é algo vivenciado com grande surpresa para alguns/ $\operatorname{algumas}^{17}$.

A situação encontrada neste estudo corrobora as colocações de $\operatorname{Peres}^{18}$, de que muitas travestis são alvo de agressões verbal e física ainda na família, sendo expulsas de suas casas e tendo que recorrerem a amigos ou outras pessoas em busca de acolhimento.

Deixar o lar é momento crucial no processo de construção dessas pessoas ${ }^{2}$. A saída do lar está ligada a não aceitação dos familiares em relação às novas descobertas e mudanças relacionadas ao corpo e a sexualidade, está ligada as intervenções corporais que não tem mais retorno quando são feitas, como o uso dos hormônios e a aplicação de silicone.

Não encontrando espaço no contexto familiar para expressarem sua identidade de gênero, entram em contato com novas perspectivas de vida e começam a surgir outros sofrimentos, marcados por agressões físicas e psicológicas, histórias de discriminação e exclusão.

Esse processo de exclusão se desenvolve como ondas, propagando-se da família para a comunidade, desta para escola, para os serviços de saúde e demais espaços e contextos de relações com que essas pessoas venham a interagir $^{18}$.

Contudo, pesquisas recentes ${ }^{19,20}$ apontam que uma mudança pode estar em curso no sentido de uma maior aceitação das famílias para com as pessoas transgênero, em comparação com travestis e transexuais pertencentes a gerações mais antigas. As adolescentes travestis acompanhadas no estudo de Monzeli ${ }^{19}$, diferentemente 
das participantes desse estudo, viviam todas com as suas famílias, algumas inclusive encontrando espaço para expressar seu gênero sem restrições familiares.

A diferença entre os estudos, em relação à preservação dos vínculos familiares, pode decorrer da diferença geracional entre os dois grupos estudados, de modo que o que era antes visto como impossibilidade e restrição, agora faz parte do cotidiano de algumas famílias ${ }^{19}$.

\section{A escola como lócus de reprodução do preconceito e discriminação}

Segundo os relatos, a escola não se configura como uma experiência positiva para as travestis e mulheres transexuais, que continuam sofrendo agressões físicas e verbais nesse novo contexto de sociabilidade. Desprovidas do acolhimento familiar, muitas não conseguem sequer chegar a frequentar a escola, e quando conseguem, se deparam com um novo contexto de sociabilidade que, na maioria dos casos, irá reproduzir o preconceito e a discriminação.

Na escola fui me misturando mais com as meninas, e os meninos falavam: - olha pra bichinha! Andando com as meninas! (Participante 2).

Na escola eu me vestia de mulher e os meninos ficavam rindo, falando 'olha professora, é viado! É mulherzinha!' Eu sofria muito! (Participante 4).

Além das agressões e insultos advindos dos estudantes, outras formas de violência também se manifestam a partir da organização da própria instituição escolar e do seu sistema de normas disciplinares, reproduzido por muitos alunos e por outros membros da comunidade escolar, como professores, diretores, etc.

A escola me proibia de usar roupa feminina, no começo eu usava duas roupas, uma masculina por cima da feminina e quando terminava a aula eu ficava com a feminina. $\mathrm{Na}$ sexta série eu cansei e enfrentei a escola, comecei a usar roupas de mulher, depois disso eu sempre me vesti como eu quero, porém, na época, até ameaçada de morte eu fui por me vestir como mulher. (Participante 1).

A escola é um espaço onde ocorrem novas descobertas, onde as pessoas têm contato com uma diversidade de conhecimentos e de pessoas, o que poderia se configurar como algo positivo na vida daqueles que a frequentam. Contudo, enquanto instituição que seria de proteção, ao mesmo tempo em que reconhece e defende a importância da integração, do respeito e da boa convivência, estabelece os possíveis modos de ser para estar nela através de regras que reproduzem os padrões heteronormativos dominantes da sociedade e que se tornam critérios seletivos geradores de exclusão $^{19}$.

Nesse sentido, quando a escola, que no discurso e em termos legais, preza pela universidade do acesso, proíbe que estas pessoas se vistam de acordo com o gênero com o qual se identificam,

[...] acaba por evidenciar os pré-requisitos necessários para a admissão dos estudantes, sendo a coerência (entre sexo, gênero e sexualidade) sua maior condição, tendo como resultado a impossibilidade de acesso e circulação, neste espaço, de algumas pessoas que não se enquadram nestas normas (p.73) ${ }^{19}$.

Sistemas de seleção discriminatórios se fazem presentes não só nas escolas, mas na maior parte das instituições pelas quais as pessoas transgênero circulam, efetivando a inserção por meio do que Monzeli ${ }^{19}$ denomina de "admissões condicionadas". Essa forma de admissão evidencia o papel seletivo e prescritivo das instituições, e mesmo que a garantia do acesso, permanência e cuidado são seus princípios orientadores, quando se trata do contato com as diferenças étnicas, sexuais, religiosas, de classe social, entre outras, tais instituições prescrevem e reafirmam formas ditas coerentes de acesso, inserção e participação ${ }^{19}$.

Isto confirma que os processos de estigmatização e violências, também se manifestam com frequência nos diversos espaços institucionais, como a escola, em relação às expressões travestis e transexuais ${ }^{21}$.

A legislação educacional, como a Lei de Diretrizes e Bases da Educação (LDB) e os Parâmetros Curriculares Nacionais (PCNs) preconizam práticas inclusivas. No entanto, a escola é um micro espaço institucional, reflete as representações sociais hegemônicas e contra-hegemônicas em disputa no macro-social e em suas outras instituições. As contradições pertinentes às disputas de poder entre valores, aceitação ou não de diferenças, fazem parte da contemporaneidade. A escola vivencia essas contradições e muitos profissionais da educação se empenham para que as escolas se tornem espaços acolhedores do diverso e menos repleto de violências simbólicas, verbais e físicas.

As manifestações discriminatórias por parte da comunidade escolar contribuem para efetivar uma intensa segregação das pessoas transgênero, por meio da limitação da participação destas no espaço social, ao serem julgadas como fora da realidade heteronormativa, onde não existe espaço para outras expressões de gênero fluir ${ }^{18}$. 


\section{A rua que acolhe e vulnerabiliza}

Ante os insultos e vivências negativas no contexto escolar, as travestis e transexuais participantes da pesquisa não se percebem pertencentes ao espaço da escola, se sentem fragilizadas e saem em busca de outros contextos de sociabilidade, nos quais se sintam aceitas. É quando, geralmente, conhecem outra travesti ou transexual mais velha e experiente, que as acolhem e acaba sendo como uma 'mãe' ou 'madrinha', inclusive apresentando novas técnicas para melhorar a aparência feminina e também a vida noturna na rua.

Eu estudava à noite, mas conheci uma travesti cabeleireira e outra que frequentava a avenida, na prostituição. Me fez o convite para eu comparecer na avenida e colocou minha primeira roupa de mulher, foi quando eu vi que fiquei bem... Eu abandonei também a escola (Participante 2).

Eu caí na rua com meus 14 anos de idade, foi quando tive que sair de casa, fui expulsa pela minha mãe e meus irmãos e vim aqui para Alagoas. Foi quando eu tive noção de que o mundo não era o que eu imaginava, nem tudo era felicidade, eu tive que sofrer muito na rua para sobreviver, foi quando eu comecei a me prostituir. (Participante 3)

Eu tive que me adaptar a todas as coisas novas. Viver longe da minha família, não tinha ninguém para mim, eu fiquei sozinha, tive que abandar os estudos, abandonei o serviço e gostei da prostituição, é uma forma bonita, ganhei muito dinheiro, mas é um dinheiro que vem fácil e vai fácil se você não tiver cabeça para investir. (Participante 4)

Já encarei muito a violência, os preconceitos, continuo encarando. Há pouco fui vitima, eu tava no ponto de ônibus e chegou um indivíduo com graça, com homofobia, veio me agredir e revidei, eu acabei caindo e machucando a perna em dois lugares. (Participante 5)

A rua é um espaço comum para todas as travestis e transexuais participantes da pesquisa. Ela é apresentada, assim como no estudo de Monzeli ${ }^{19}$, como um espaço receptivo, que apesar de oferecer inúmeros riscos, possibilita a construção de uma nova rede de apoio social baseada na experiência comum da vulnerabilidade. A rua apresentase como espaço de sociabilidade por onde elas circulam durante o dia e também espaço de trabalho a noite. Pois é através da prostituição noturna que elas encontram aquele que parece o único meio de ter uma renda para suprirem as suas necessidades e sobreviverem.

A prostituição se faz presente na vida delas desde muito cedo, sendo encarada com naturalidade. Os fatores que as levam a essa situação são profundos e decorrem, de um modo geral, das desvantagens sociais advindas da expressão do gênero, resguardando as singularidades das histórias de vida de cada uma.

Ainda muito jovens, entram em contato com novas perspectivas, inclusive as de modificações corporais, e começam a aprender como se tornar mais feminina, a sobreviver com o dinheiro da prostituição e a se proteger dos perigos da rua.

A rua, apesar de também ter as suas normas de convivência, permite uma maior circulação para estas pessoas, que vivenciam não só situações de risco e violência, mas também de prazer e aceitação.

A discussão aqui apresentada possibilitou identificar e entender as vivências das travestis e mulheres transexuais em alguns dos contextos de sociabilidade e que marcam as suas trajetórias de vida. Apesar de terem as suas particularidades, foi possível identificar que as vivências relativas à expressão de gênero das travestis e transexuais da pesquisa apresentam muitas semelhanças.

\section{CONSIDERAÇÕES FINAIS}

As pessoas transgênero compõem a sociedade e revelam a diversidade que a mesma comporta. Contudo, o modelo de sociedade dominante tende a negar e excluir as diversidades humanas e valorizar a homogeneização do ser humano, de modo que os processos sociais de normatização existentes desqualificam e até mesmo excluem essas diversidades do convívio social, taxando de inferior tudo que foge ao padrão estabelecido.

A partir deste estudo, constatou-se que as identidades transgênero, quando expressadas na sociedade, tendem a empurrar as travestis e transexuais para uma situação de vulnerabilidade social, marcada pela fragilidade dos vínculos de trabalho ou das relações sociais, e que determina uma restrição na participação social destas pessoas em igualdade de direitos, caracterizando a condição de desvantagem social. Este processo afeta a autonomia, os direitos e o empoderamento pessoal e social das mesmas.

Ficou evidente que essas pessoas passam por várias situações que levam a sofrimentos diversos. Espaços que deveriam se configurar como importantes suportes na vida, como a família e a escola, tornam-se espaços de exclusão a partir das primeiras manifestações da diferença.

A realidade apresentada coloca desafios para os profissionais, dentre eles o terapeuta ocupacional, que lidam com o enfrentamento das situações de exclusão e vulnerabilidade, no sentido de pensar estratégias para prevenir ou reverter tal quadro. Para tanto, é preciso estar 
atento aos processos macro e micro políticos, a nível local e nacional, e conhecer as políticas públicas voltadas para melhoria da condição de vida dessas pessoas.

Dada a complexidade das demandas colocadas pela população transgênero, as propostas interventivas junto à mesma requerem a constituição de projetos intersetoriais e interdisciplinares, estabelecendo conexões entre as diferentes áreas de políticas públicas e saberes diversos para criar um campo mais efetivo técnica e politicamente de intervenção. As ações devem, sempre que possível, serem construídas também em conjunto com as próprias travestis e transexuais, favorecendo a autonomia e o empoderamento. A assistência a esta população na infância e na adolescência pode prevenir futuras situações de vulnerabilidade e risco, como a prostituição enquanto meio de trabalho e subsistência. Nas situações de vulnerabilidade já instaladas, deve-se contribuir com a (re)construção das redes de apoio social, promovendo a desconstrução dos estigmas sociais em relação as populações transgênero, além de auxiliar na elaboração conjunta de projetos de vida, onde a emancipação, o protagonismo e os direitos sociais possam ser restabelecidos na vivência das travestis e das mulheres transexuais.

\section{REFERÊNCIAS}

1. Grossi MP. Identidade de gênero e sexualidade. Antropol Primeira Mão (Florianópolis). 1998;(24) [citado 3 mar. 2015]. Disponível em: http://www.observem.com/upload/69a8d4dc 71b04390c3096c61cbc97aed.pdf.

2. Benedetti MR. Toda feita: o corpo e o gênero das travestis. Rio de Janeiro: Garamond; 2005.

3. Paixão GPN, Santos SMP, Ramos PR. Questões de gênero: percepção de adolescente no município de Juazeiro-BA. UDESC em Ação. 2008;2(1). Disponível em: http:// www.revistas.udesc.br/index.php/udescemacao/article/ view/1699/1347.

4. Silva TT. Documentos de identidade: uma introdução às teorias de currículo. 2a ed. Belo Horizonte: Autêntica; 2007.

5. Bruns MAT, Pinto MJC. Vivência transexual: o corpo desvela seu drama. Campinas, SP: Editora Átomo; 2003.

6. Peres WS. Subjetividade das travestis brasileiras: da vulnerabilidade da estigmatização à construção da cidadania [Tese]. Rio de Janeiro: Universidade do Estado do Rio de Janeiro, Instituto de Medicina Social; 2005.

7. Money J, Tucker P. Os papéis sexuais. São Paulo: Brasiliense; 1981.

8. Jesus JG. Orientações sobre identidade de gênero: conceitos e termos. Guia técnico sobre pessoas transexuais, travestis e demais transgêneros, para formadores de opinião. Brasília; 2012 [citado 23 out. 2014]. Disponível em: http://issuu.com/ jaquelinejesus/docs/orienta_es_popula_o_trans.

9. Jayme GJ. Travestis, transformistas, drag-queens, transexuais: identidade, corpo e gênero. Belo Horizonte: PUC; 2001. In: VIII Congresso Luso-Afro-Brasileiro de Ciências Sociais.
Disponível em: http://www.ces.uc.pt/lab2004/inscricao/pdfs/ painel3/JulianaJaime.pdf.

10. Miskolci R. Teoria Queer: um aprendizado pelas diferenças. Belo Horizonte: Autêntica Editora/UFPO; 2012.

11. Miskolci R. Não ao sexo rei: da estética da existência foucaultiana à política queer. In: Souza LAF, Sabatine TT, Magalhães BR, organizadores. Michel Foucault: sexualidade, corpo e direito. Marília: Cultura Acadêmica Editora; 2011. v.1, p.47-68.

12. Bento B. O que é transexualidade. São Paulo: Editora Brasiliense; 2008.

13. Jesus JG. Transfobia e crimes de ódio: assassinatos de pessoas transgênero como genocídio. In: Maranhão $\mathrm{F}^{\circ}$ EMA, organizador. (In)Visibilidade Trans 2. História Agora. 2013;16(2):101-23. Disponível em: http://jaquejesus. blogspot.com.br/2015/08/transfobia-e-crimes-de-odio.html.

14. Kulick D. Travesti: prostituição, sexo, gênero e cultura no Brasil. Rio de Janeiro: Editora Fiocruz; 2008.

15. Guimarães LD. A sociabilidade e seus espaços: um estudo histórico a partir de seus intérpretes [Dissertação]. Rio de Janeiro: UFRJ/PROURB/Programa de PósGraduação em Urbanismo; 2008. Disponível em: http:// www.dominiopublico.gov.br/pesquisa/DetalheObraForm. do?select_action=\&co_obra $=163764$.

16. Jesus JG. Crianças trans: memórias e desafios teóricos. In: Anais do III Seminário Internacional Enlaçando Sexualidades, Salvador, Bahia; 2013. Disponível em: http://www.uneb.br/ enlacandosexualidades/files/2013/06/Crian\%C3\%A7astrans-mem $\% \mathrm{C} 3 \% \mathrm{~B} 3$ rias-e-desafios-te $\% \mathrm{C} 3 \% \mathrm{~B} 3$ ricos.pdf. 
Silva RGLB, et al. Os impactos das identidades transgênero. Rev Ter Ocup Univ São Paulo. 2015 set.-dez.;26(3):364-72.

17. Bento B. A diferença que faz a diferença: corpo e subjetividade na transexualidade. Bagoas Rev Estudos Gays. 2009;3:95112. Disponível em: http://www.periodicos.ufrn.br/bagoas/ article/view/2298.

18. Peres WS. Travestis Brasileiras: construindo Identidades cidadãs. In: Grossi MP, et al., organizadores. Movimentos sociais, educação e sexualidades. Rio de Janeiro: Garamond; 2005.

19. Monzeli GA. Em casa, na pista ou na escola é tanto babado: espaços de sociabilidade de jovens travestis [Dissertação]. São Carlos: Universidade Federal de São Carlos; 2013. Disponível em: http:/www.bdtd.ufscar.br/htdocs/tedeSimplificado/ tde_busca/arquivo.php?codArquivo $=5844$.

Artigo recebido em: 24.11 .14

Artigo aceito em: 25.08.15
20. Duque T. Montagens e desmontagens: vergonha, estigma e desejo na construção das travestilidades na adolescência [Dissertação]. São Carlos: Universidade Federal de São Carlos, Programa de Pós-Graduação em Sociologia; 2009. Disponível em: http://www.ufscar.br/cis/wp-content/ uploads/2539.pdf.

21. Peres WS. Cenas de exclusões anunciadas: travestis, transexuais, transgêneros e a escola brasileira. In: Junqueira RD, organizador. Diversidade sexual na educação: problematização sobre a homofobia nas escolas. Brasília: Ministério da Educação, Secretaria de Educação Continuada, Alfabetização e Diversidade, UNESCO; 2009. p.235-63. Disponível em: http://unesdoc.unesco.org/ images/0018/001871/187191por.pdf. 